\title{
Methylation profiles of endometrioid and serous endometrial cancers
}

\author{
Laura M S Seeber, Ronald P Zweemer, Luigi Marchionni, \\ Leon F A G Massuger ${ }^{2}$, Vincent T H B M Smit ${ }^{3}$, W Marchien van Baal ${ }^{4}$, \\ René $H$ M Verheijen and Paul J van Diest ${ }^{5}$
}

\begin{abstract}
Department of Gynaecological Oncology, University Medical Centre Utrecht, 3508 GA Utrecht, The Netherlands
${ }^{1}$ Department of Oncology, Johns Hopkins Oncology Center, The Sidney Kimmel Comprehensive Cancer Center, Johns Hopkins University - School of Medicine, 1550 Orleans Street, CRB2, Room 554, Baltimore, Maryland 21231, USA

${ }^{2}$ Department of Obstetrics and Gynaecology (791), Radboud University Nijmegen Medical Centre, PO Box 9101, 6500 HB Nijmegen, The Netherlands

${ }^{3}$ Department of Pathology, Leiden University Medical Centre, L1Q, PO Box 9600, 2300 RC Leiden, The Netherlands

${ }^{4}$ Department of Gynaecological Oncology, VU University Medical Centre, PO Box 7057, 1007 MB Amsterdam, The Netherlands

${ }^{5}$ Department of Pathology, University Medical Centre Utrecht, H04-312, PO Box 85500, 3508 GA Utrecht, The Netherlands
\end{abstract}

(Correspondence should be addressed to P J van Diest; Email: p.j.vandiest@ umcutrecht.nl)

\begin{abstract}
Promoter methylation is a gene- and cancer type-specific epigenetic event that plays an important role in tumour development. As endometrioid (endometrioid endometrial carcinoma, EEC) and serous endometrial cancers (uterine papillary serous carcinoma, UPSC) exhibit different clinical, histological and molecular genetic characteristics, we hypothesized that these differences may be reflected in epigenetic phenomena as well. Identification of a panel of methylation biomarkers could be helpful in a correct histological classification of these two subtypes, which solely on the basis of morphology is not always easy. Methylation-specific multiplex ligation-dependent probe amplification was used to assess the extent of promoter methylation of different tumour suppressor genes in EEC and UPSC. Methylation results were correlated with histology and survival. The median cumulative methylation index of all genes was significantly higher in EEC $(124)$ than in UPSC $(93)(P<0.001)$. Promoter methylation of $\mathrm{CDH} 13$ and MLH1 was more frequently present in EEC, while CDKN2B and TP73 were more frequently methylated in UPSC. Almost $90 \%$ of EEC and $70 \%$ of UPSC could be predicted by $\mathrm{CDH} 13$ and TP73. In EEC, methylation of MLH1 was associated with a shorter disease-free survival (DFS; $P<0.0001$ ) and overall survival (OS; $P=0.005)$. In a multivariate model, MLH1 methylation emerged as an additional prognostic factor to stage for DFS $(P=0.002)$. In conclusion, promoter methylation is more common in EEC than UPSC. A panel of methylation biomarkers could be useful to distinguish between the two histological subtypes of endometrial cancer. Furthermore, methylation of MLH1 may have prognostic value in EEC.
\end{abstract}

Endocrine-Related Cancer (2010) 17 663-673

\section{Introduction}

Tumours presumably develop by a stepwise accumulation of interacting epigenetic and genetic events over time (Baylin \& Herman 2000, Jones \& Baylin 2002). Promoter methylation is an epigenetic event that plays an important role in both normal and tumour cells. In normal cells, it contributes to chromatin organization, silencing of transposable elements, X-chromosome inactivation, tissue-specific expression and genetic imprinting. In cancer cells, besides global hypomethylation of the genome, methylation of $\mathrm{CpG}$ islands occurs (Baylin \& Herman 2000). These CpG islands are cytosine- and guanine-rich areas in the promoter regions of genes that are involved in cell cycle, cell adherence, DNA repair and apoptosis. Methylation of the $\mathrm{CpG}$ islands leads to inactivation of these genes (Baylin \& Herman 2000, Jones \& Baylin 2002). CpG island methylation is gene-specific and cancer type-specific (Costello et al. 2000, Yang et al. 2006, Esteller 2008). Specific methylation patterns 
may provide a useful signature for tumour diagnosis and may be used to assess prognosis.

In the Western world, endometrial cancer is the most common malignant tumour of the female genital tract. The American Cancer Society estimates that 42160 women will have been diagnosed with, and 7780 women will have died of endometrial cancer in 2009 in the USA (Jemal et al. 2009). In the endometrium, different subtypes of cancer can develop. Endometrioid endometrial carcinoma (EEC), or type 1 cancer, accounts for $\sim 75 \%$ of cases. These tumours are oestrogen-dependent and tend to be of lower grade, and have fewer recurrences and a better survival than other types. They often develop in a background of atypical complex hyperplasia and are sometimes characterized by mutations in phosphatase and tensin homologue (PTEN) and defects in DNA mismatch repair - as manifested by microsatellite instability (MSI). Ninety percentage of EEC cases are sporadic, while the remaining $10 \%$ are hereditary. For example, germ line mutations in the mismatch repair genes ( $M L H 1$, MSH2, MSH6 and PMS2) result in Lynch syndrome, a familial syndrome associated with elevated risk of colorectal cancer and EEC (Bocker et al. 1999). Type 2 tumours, of which uterine papillary serous carcinoma (UPSC) is the most common subtype, arise from atrophic endometrium in older women. Its precursor lesion endometrial intraepithelial carcinoma (EIC) also differs as compared with EEC. These type 2 tumours are often poorly differentiated, and have a greater propensity for early spread and a worse prognosis than EEC. So far, they have not been associated with a hereditary tumour syndrome. Type 2 tumours often contain p53 mutations and are usually non-diploid. Although these specific genetic alterations have been described in endometrial cancers, none of these changes occur in a majority of cases. UPSC is rare, mixed patterns - defined as UPSC with a component of adenocarcinoma - do occur (Sherman et al. 1992), and diagnosis of UPSC, based on histology and p53 immunohistochemistry, may therefore be difficult. Moreover, some EEC does show a villoglandular and even papillary growth pattern that may mimic UPSC. Since classification as EEC and UPSC has therapeutic and prognostic implications, it is important to make the proper diagnosis. In view of the described differences in clinical, histological and molecular genetic characteristics of EEC and UPSC, we hypothesized that these differences also extend to methylation patterns. In EEC, methylation of MLH1 (Esteller et al. 1999, Horowitz et al. 2002, Kanaya et al. 2003), RARb2 (Arafa et al. 2008), RASSF1 (Arafa et al. 2008) and CDKN2A (p16) (Guida et al. 2009) has been suggested as early events in carcinogenesis. Many other epigenetically silenced genes have been described in EEC, such as MGMT (Furlan et al. 2006), PTEN (Salvesen et al. 2001, Macdonald et al. 2004) and GSTP1 (Chan et al. 2005). However, little is yet known about the role of methylation in UPSC (Xiong et al. 2005, Xie et al. 2007). Establishment of methylation profiles could improve our understanding of carcinogenesis in both subtypes of endometrial cancer and may lead to identification of a panel of methylation biomarkers, which can be used as an additional tool for correct classification of these two histological subtypes. Therefore, the aim of our study was to compare methylation status of a set of common tumour suppressor genes (TSGs) in EEC and UPSC, in order to arrive at a methylation signature of EEC and UPSC, and to evaluate prognostic value of methylation.

\section{Materials and methods}

\section{Patients and tissues}

Paraffin-embedded specimens from EEC $(n=93)$ and UPSC $(n=26)$ were selected from the archives of the Department of Pathology of the University Medical Centre, Utrecht, The Netherlands, with additional samples of UPSC from the University Medical Centre Nijmegen, Leiden University Medical Centre and the VU University Medical Centre Amsterdam. Only patients with hysterectomy samples available were included. Furthermore, patients were excluded if they had a second primary tumour of the cervix or ovary, or a history of cervical carcinoma. None of the patients received preoperative radio- or chemotherapy. Haematoxylin- and eosin-stained sections were revised and histologically typed and graded by two pathologists. The tumour stage and grade were defined by the International Federation of Gynaecology and Obstetrics (FIGO) system (Creasman et al. 2006). Histological grading only applied to EEC; UPSC is considered high grade by definition. Anonymous use of redundant tissue for research purposes is part of the standard treatment agreement with patients in our network hospitals (van Diest 2002).

Table 1 gives an overview of the baseline clinicopathological features. There was a significant correlation between tumour type and p53 positivity $(P<0.0001)$, with p53 being positive in $21 \%$ of EEC and in $62 \%$ of UPSC.

Survival analysis was restricted to EEC since there were too few UPSC cases for meaningful statistics. In EEC, three patients with unknown recurrence status were censored for disease-free survival (DFS) analysis. Locoregional recurrences (vaginal, pelvic or both) or 
Table 1 Patient demographics and main pathological features of the study group of endometrial cancer patients $(n=119)$

\begin{tabular}{|c|c|c|}
\hline Variable & Grouping & $N(\%)$ \\
\hline \multicolumn{3}{|l|}{ Endometrioid $(n=93)$} \\
\hline \multirow[t]{3}{*}{ Age } & Minimum & 40 \\
\hline & Maximum & 88 \\
\hline & Mean & 63 \\
\hline \multirow[t]{4}{*}{ Stage } & I & $55(59)$ \\
\hline & II & $22(24)$ \\
\hline & III & $11(12)$ \\
\hline & IV & $5(5)$ \\
\hline \multirow[t]{3}{*}{ Grade } & 1 & $28(30)$ \\
\hline & 2 & $46(50)$ \\
\hline & 3 & $19(20)$ \\
\hline \multirow[t]{3}{*}{ Grade 2nd revision } & 1 & $56(47)$ \\
\hline & 2 & $10(8)$ \\
\hline & 3 & $27(25)$ \\
\hline \multirow{3}{*}{$\begin{array}{l}\text { Depth of myometrial } \\
\text { invasion }\end{array}$} & 0 & $3(3)$ \\
\hline & $<50 \%$ & $49(53)$ \\
\hline & $>50 \%$ & $41(44)$ \\
\hline \multirow{3}{*}{$\begin{array}{l}\text { Recurrence/ } \\
\text { metastasis }\end{array}$} & Yes & 17 (19) \\
\hline & No & $73(75)$ \\
\hline & Missing & $3(6)$ \\
\hline \multirow[t]{5}{*}{ Survival } & Alive & $68(73)$ \\
\hline & $\begin{array}{l}\text { Death of endometrial } \\
\text { cancer }\end{array}$ & $10(11)$ \\
\hline & $\begin{array}{l}\text { Death of intercurrent } \\
\text { disease }\end{array}$ & $11(12)$ \\
\hline & Cause of death unknown & $3(3)$ \\
\hline & Missing & $1(1)$ \\
\hline \multicolumn{3}{|l|}{ Serous $(n=26)^{\mathrm{a}}$} \\
\hline \multirow[t]{3}{*}{ Age } & Minimum & 57 \\
\hline & Maximum & 88 \\
\hline & Mean & 69 \\
\hline \multirow[t]{4}{*}{ Stage $^{b}$} & I & $8(31)$ \\
\hline & II & $7(27)$ \\
\hline & III & $7(27)$ \\
\hline & IV & $3(11)$ \\
\hline \multirow{3}{*}{$\begin{array}{l}\text { Depth of myometrial } \\
\text { invasion }^{\mathrm{b}}\end{array}$} & 0 & $1(4)$ \\
\hline & $<50 \%$ & $6(23)$ \\
\hline & $>50 \%$ & 18 (69) \\
\hline
\end{tabular}

aSerous endometrial carcinoma is considered high grade by definition.

${ }^{\mathrm{b}}$ Stage and MI missing for $n=1$.

distant metastases were found in 17 of 90 patients. The follow-up was 12-182 months (mean 72 months) for surviving patients.

\section{Immunohistochemistry}

Immunohistochemistry was performed on $4 \mu \mathrm{m}$-thick paraffin slides. Slides were deparaffinized with xylene and serial ethanol dilutions, and endogenous peroxidase activity was blocked in a buffer solution of $\mathrm{pH}$ 5.8 with hydrogen peroxide followed by antigen retrieval. Antigen retrieval was performed with citrate buffer, $\mathrm{pH}$ 6.0, for $20 \mathrm{~min}$ at boiling temperature.
After a cooling down period of $20 \mathrm{~min}$, the slides were incubated with the primary p53 antibody (DakoCytomation, Glostrup, Denmark) for $1 \mathrm{~h}$ at room temperature, followed by the secondary antibody (Powervision, ImmunoVision Technologies, Brisbane, CA, USA; ready to use, $30 \mathrm{~min}$ ). Slides were developed with diaminobenzidine for $10 \mathrm{~min}$, followed by haematoxylin counterstaining. In between steps, slides were washed in PBS. Before the slides were mounted, all sections were dehydrated in alcohol and xylene. Appropriate positive and negative controls were used throughout.

\section{Evaluation of staining}

Two authors ( $\mathrm{P} \vee \mathrm{D}$ and $\mathrm{L} \mathrm{S}$ ) scored all slides blinded to clinico-pathological data and promoter methylation results. The percentage of dark, homogenously stained nuclei was estimated, ignoring wild-type staining. p53 nuclear staining in more than $10 \%$ of cells was considered as positive (Fig. 1). Staining was evaluated through a standard light microscope (Leica DM6000B) at $200-400 \times$ final magnification. Pictures were taken with a Leica digital camera DMX1200 through a $10 \times$ objective.

\section{DNA extraction}

Paraffin sections of $4 \mu \mathrm{m}$ were cut, placed on slides and dried overnight. After deparaffinization, mesodissection of the relevant tissue was performed with a scalpel on the basis of marked haematoxylin- and eosinstained serial sections. The tissue was suspended in $100 \mu \mathrm{l}$ lysis buffer $(50 \mathrm{mM}$ Tris- $\mathrm{HCl}, \mathrm{pH} 8.0 ; 0.5 \%$

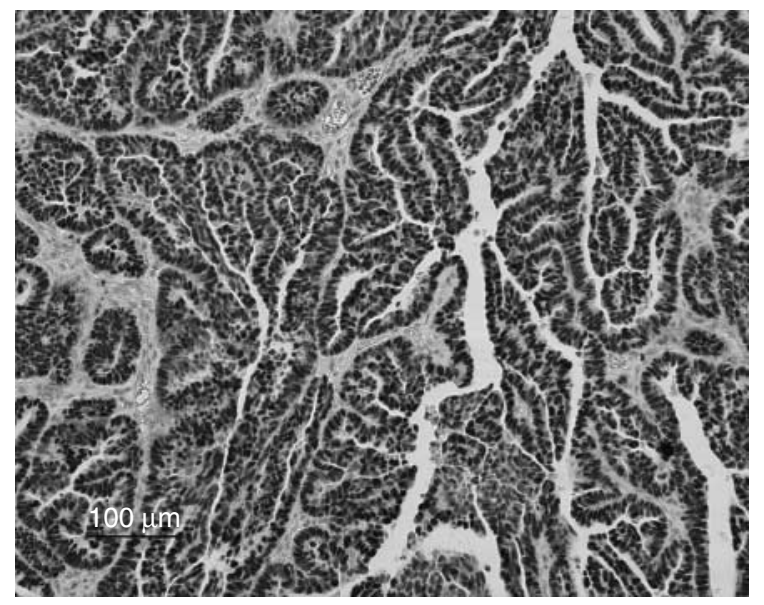

Figure 1 Positive p53 nuclear immunohistochemical staining in serous endometrial cancer tissue. Positive staining in more than $10 \%$ of cells was considered as positive. 
Tween 20). Two hundred milligrams of proteinase $\mathrm{K}$ (Sigma) were added. After $1 \mathrm{~h}$ incubation at $56^{\circ} \mathrm{C}$, samples were heat inactivated for $10 \mathrm{~min}$ at $99^{\circ} \mathrm{C}$ and immediately placed on ice. Samples were subsequently centrifuged for $2 \mathrm{~min}$ at 14000 r.p.m. (22 $000 \mathrm{~g})$, after which the supernatant was stored at $4{ }^{\circ} \mathrm{C}$.

\section{Methylation-specific multiplex ligation-dependent probe amplification}

The ME001 methylation-specific multiplex ligationdependent probe amplification (MS-MLPA) probe mix (MRC Holland, Amsterdam, The Netherlands) was used to study promoter methylation of 24 TSGs (see Table 2 for list of genes). These TSGs are known to be frequently silenced by methylation in different tumours. The principle of the MS-MLPA technique has been described elsewhere (Nygren et al. 2005). The experimental procedure followed the recommendations of the manufacturer. Reaction products were separated by capillary electrophoresis (on an ABI 310 automated DNA sequencer, Applied Biosystems, Foster City, CA, USA) and analysed using GeneScan genotyping software (Applied Biosystems). The method is based on probes that target $\mathrm{CpG}$ islands within the promoter regions of the TSGs. The probes

Table 2 Tumour suppressor genes studied

\begin{tabular}{|c|c|}
\hline $\begin{array}{l}\text { Gene } \\
\text { symbols }\end{array}$ & Gene names \\
\hline$A P C$ & Adenomatous polyposis coli \\
\hline ATM & Ataxia telangiectasia mutated \\
\hline$B R C A 1$ & Breast cancer type 1 susceptibility protein \\
\hline$B R C A 2$ & Breast cancer type 2 susceptibility protein \\
\hline CASP8 & Caspase 8 \\
\hline CD44 & CD44 antigen precursor \\
\hline $\mathrm{CDH13}$ & Cadherin $13, \mathrm{H}$-cadherin \\
\hline$C D K N 1 B$ & Cyclin-dependent kinase inhibitor 1B (p27 kip) \\
\hline CDKN2A & $\begin{array}{l}\text { Cyclin-dependent kinase inhibitor } 2 \mathrm{~A} \text { (encoding } \\
\text { p14ARF) }\end{array}$ \\
\hline$C D K N 2 B$ & Cyclin-dependent kinase inhibitor 2B (p15) \\
\hline CHFR & $\begin{array}{l}\text { Checkpoint protein with forkhead and RING } \\
\text { finger domains }\end{array}$ \\
\hline$D A P K 1$ & Death-associated protein kinase 1 \\
\hline ESR1 & Oestrogen receptor 1 \\
\hline FHIT & Fragile histidine triad gene \\
\hline GSTP1 & Glutathione $S$-transferase pi \\
\hline HIC1 & Hypermethylated in cancer 1 \\
\hline IGSF4 & Immunoglobulin superfamily, member 4 \\
\hline MLH1 & MutL homologue 1 \\
\hline PTEN & Phosphatase and tensin homologue \\
\hline$R A R \beta$ & Retinoic acid receptor, $\beta$ \\
\hline RASSF1A & RAS-associated domain family 1 (isoform A) \\
\hline TIMP3 & Tissue inhibitor of metalloproteinases 3 \\
\hline TP73 & Cellular tumour antigen p73 \\
\hline$V H L$ & Von Hippel-Lindau disease tumour suppressor \\
\hline
\end{tabular}

contain a recognition site for the methylation-sensitive restriction enzyme HhaI. HhaI digests unmethylated DNA but leaves methylated sites intact, generating a signal if DNA is undigested. The peak area of each probe was normalized by dividing it by the combined areas of the control probes. Each normalized peak area from a digested sample was compared with that obtained in the undigested sample. The peak sizes and areas were exported to an Excel file, and the normalized areas from the digested and undigested samples were compared to determine the methylation dosage ratio. This is described by the following calculation: $D_{\mathrm{m}}=\left(P_{\mathrm{x}} / P_{\mathrm{ctrl}}\right)_{\mathrm{Dig}} /\left(P_{\mathrm{x}} / P_{\mathrm{ctrl}}\right)_{\mathrm{Lig}}$, where $D_{\mathrm{m}}$ is the methylation dosage ratio, $P_{\mathrm{x}}$ is the peak area of a given probe, $P_{\text {ctrl }}$ is the sum of the peak areas of all control probes. Dig stands for HhaI digested sample and Lig for undigested sample. Based on previous cell line experiments (Gylling et al. 2007, Joensuu et al. 2008), we considered a promoter to show methylation if the methylation dosage ratio was $\geq 0.15$, which corresponds to $15 \%$ of DNA methylated. All cases were analysed in duplicate, using the mean methylation percentage of the two runs in the statistical analysis. The cumulative methylation index (CMI) was calculated as the sum of the percentage methylation for all genes as before (Suijkerbuijk et al. 2008; Supplementary Figure 1, see section on supplementary data given at the end of this article).

\section{Statistical analysis}

Mann-Whitney and Kruskal-Wallis tests were used for comparing medians between groups. The $\chi^{2}$-test was used for comparing proportions. Spearman correlation coefficients were computed for assessing the association between methylation and other continuous variables. Hierarchical clustering was applied using R and SPSS (Chicago, IL, USA). We performed logistic regression analysis to examine the predictive value of methylation pattern on tumour type, calculating $95 \%$ confidence intervals (CI) of the regression coefficients. Univariate survival analysis was restricted to EEC since there were too few UPSC cases for meaningful statistics. Kaplan-Meier curves were plotted, and differences between the curves were analysed with the log-rank test. The covariates stage, grade and myometrial invasion were next to methylation data used in multivariate analysis by Cox regression. Statistical tests were considered statistically significant at two-sided $P \leq 0.05$. SPSS 15.0 for Windows was used for statistical analysis. 


\section{Results}

\section{Overall frequencies of promoter methylation}

Using a methylation dosage ratio of 0.15 as threshold, an average of three TSGs were methylated per tumour. There was a significant difference in the number of methylated genes between EEC (average 3.0 genes) and UPSC (average 2.0 genes) ( $t$-test; $P=0.008$ ). In individual tumours, the number of methylated genes ranged from 0 to 7 . Of the six tumours showing no methylation at all, five were UPSC.

\section{Methylation patterns of individual genes}

Aberrant methylation in at least $20 \%$ of the cases was observed for five genes in EEC (TIMP3, APC, RASSF1, $C D H 13$ and $M L H 1$ ) and for four genes in UPSC (CDKN2B, RASSF1, TP73 and CDH13). CDH13 was most frequently methylated in $101 / 120$ cases. RASSF 1 showed frequent methylation in both cancers. Among genes showing significant tumour-type specificity, methylation of TIMP3, CDH13 and $M L H 1$ was more frequently found in EEC. Interestingly, $M L H 1$ was never methylated in UPSC. Methylation of $C D K N 2 B$ and TP73 was not very frequent, but if present, it was quite typical of UPSC (27 vs $9 \%$ and 20 vs $4 \%$ respectively). Methylation of the frequently methylated genes was not correlated with stage. Only $\mathrm{CDH} 13$ methylation was correlated with age; the mean age in the unmethylated cases was significantly higher $(P=0.016)$. In the EEC cases, $C D H 13$ was significantly less frequently methylated in grade 3 tumours $(P=0.002)$. In the PORTEC-1 trail (Scholten et al. 2004), the reproducibility of grade 2 was found to be poor; therefore, a second revision of grade was done (V S) (Table 1) Again, only a correlation between CDH13 methylation and grade was found. When comparing grade 3 EEC and UPSC, APC and MLH1 were significantly more often methylated in EEC, and $C D K N 2 B$ was methylated in UPSC. Of the 24 TSGs, ATM, HICl, CDKN1B, BRCA2, DAPK1 and VHL1 were never methylated in EEC or UPSC.

Table 3 Tumour suppressor gene methylation profiles in 119 endometrial cancers

\begin{tabular}{|c|c|c|c|c|c|c|}
\hline \multirow[b]{2}{*}{ Genes } & \multicolumn{3}{|c|}{ Endometrioid } & \multicolumn{3}{|c|}{ Serous } \\
\hline & $\begin{array}{c}\text { Freq meth cases } \\
(\%)\end{array}$ & $\begin{array}{c}\text { Quantitative } \\
\text { methylation } \\
\text { levels in \% } \\
\text { (range) }\end{array}$ & Mean \% & $\begin{array}{c}\text { Freq meth cases } \\
(\%)\end{array}$ & $\begin{array}{c}\text { Quantitative } \\
\text { methylation } \\
\text { levels in \% } \\
\text { (range) }\end{array}$ & Mean \% \\
\hline$A P C$ & $29(31)$ & $15-83$ & 47 & $5(19)$ & $24-69$ & 42 \\
\hline ATM & - & - & - & - & - & - \\
\hline$B R C A 1$ & $3(3)$ & $31-48$ & 37 & $1(4)$ & 22 & 22 \\
\hline$B R C A 2$ & - & - & - & - & - & - \\
\hline CASP8 & $6(6)$ & $16-68$ & 42 & $1(4)$ & 24 & 24 \\
\hline$C D 44$ & $4(4)$ & $22-49$ & 31 & 0 & 0 & - \\
\hline$C D H 13$ & $87(93)$ & $16-118$ & 55 & $13(50)$ & $15-81$ & 44 \\
\hline$C D K N 1 B$ & - & - & - & - & - & - \\
\hline$C D K N 2 A$ & $2(2)$ & $16-18$ & 18 & - & - & - \\
\hline$C D K N 2 B$ & $8(9)$ & $15-40$ & 22 & $7(27)$ & $15-43$ & 31 \\
\hline CHFR & $8(9)$ & $26-109$ & 58 & - & - & - \\
\hline$D A P K 1$ & - & - & - & - & - & - \\
\hline ESR1 & $2(2)$ & $20-47$ & 34 & - & - & - \\
\hline FHIT & $2(2)$ & $46-89$ & 68 & - & - & - \\
\hline GSTP1 & $14(15)$ & $0-58$ & 25 & - & - & - \\
\hline HIC1 & - & - & - & - & - & - \\
\hline IGSF4 & $2(2)$ & $20-37$ & 29 & - & - & - \\
\hline MLH1 & $24(26)$ & 14-132 & 65 & - & - & - \\
\hline PTEN & $1(1)$ & 17 & 17 & - & - & - \\
\hline$R A R B$ & $1(1)$ & 32 & 32 & $1(4)$ & 36 & 36 \\
\hline RASSF1A & $74(79)$ & $16-90$ & 51 & $20(77)$ & $16-91$ & 48 \\
\hline TIMP3 & $25(27)$ & $15-89$ & 38 & $2(8)$ & $19-51$ & 35 \\
\hline TP73 & $4(4)$ & $15-19$ & 17 & $5(20)$ & $15-19$ & 18 \\
\hline$V H L 1$ & - & - & - & - & - & - \\
\hline \multicolumn{2}{|c|}{ CMI (cumulative methylation index) } & $0-508$ & 155 & & $0-220$ & 83 \\
\hline
\end{tabular}

The bold genes are the frequently methylated genes. 


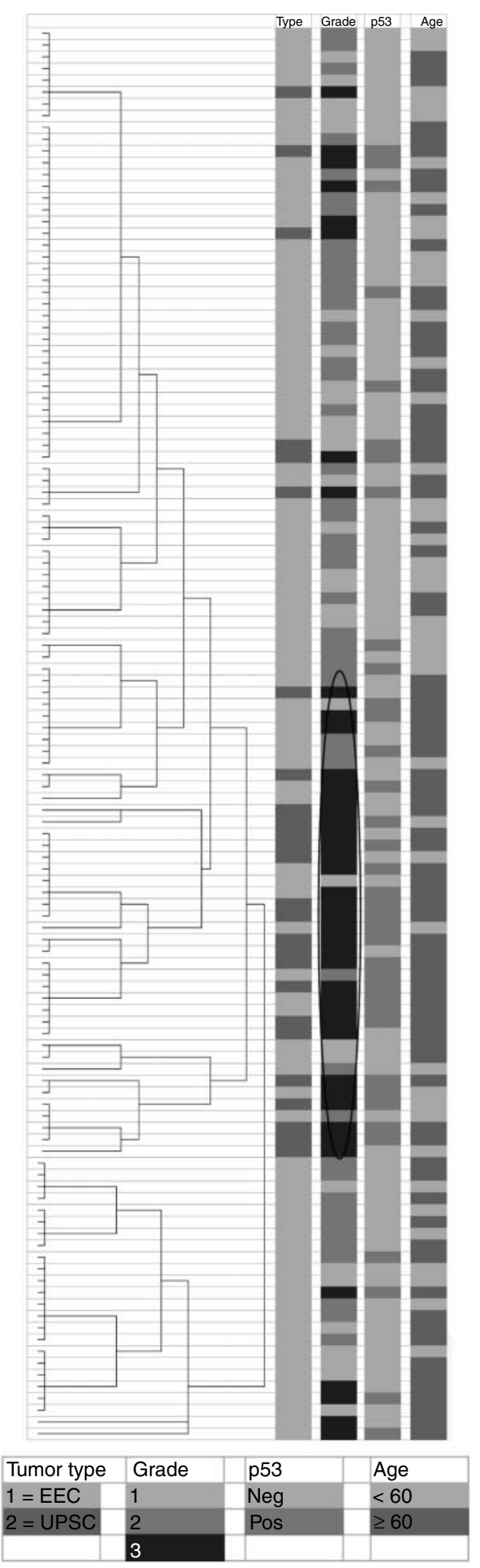

Figure 2 Clustering of samples according to the methylation status of frequently methylated genes. The dendrogram is linked to the correlated histological subtype, grade, p53 status and age.

\section{Quantitative methylation levels}

The extent of methylation of the various genes is specified in Table 3. Overall, the quantitative methylation levels were higher in EEC than in UPSC. The CMI ranged from 0 to 508, and was significantly higher in EEC (median 124) than in UPSC (median 93; $P<0.001)$. CMI was also significantly higher in grade 3 EEC compared to UPSC. High CMI ( $>124)$ was not correlated with stage, grade, age or p53 positivity. The individual methylation levels varied between the different TSGs. Of the frequently methylated genes, $M L H 1$ and $C D H 13$ showed highest quantitative methylation levels (Table 3). CDKN2B and TP73 showed the lowest mean quantitative methylation levels (26 and 17\% respectively) of those genes showing any methylation. Six genes were never methylated as stated above.

\section{Clustering and regression analysis}

Figure 2 shows clustering of the samples according to the methylation status of the frequently methylated genes. The dendrogram was linked to the correlated histological subtype, grade, p53 status and age. Unsupervised hierarchical clustering of the frequently methylated genes (APC, CDH13, MLH1, RASSF1, TIMP3, CDKN2B and TP73) segregated the tumours for the greater part into the histological subtypes. Clustering by p53 did not result in a specific pattern, nor did clustering by age at the time of diagnosis.

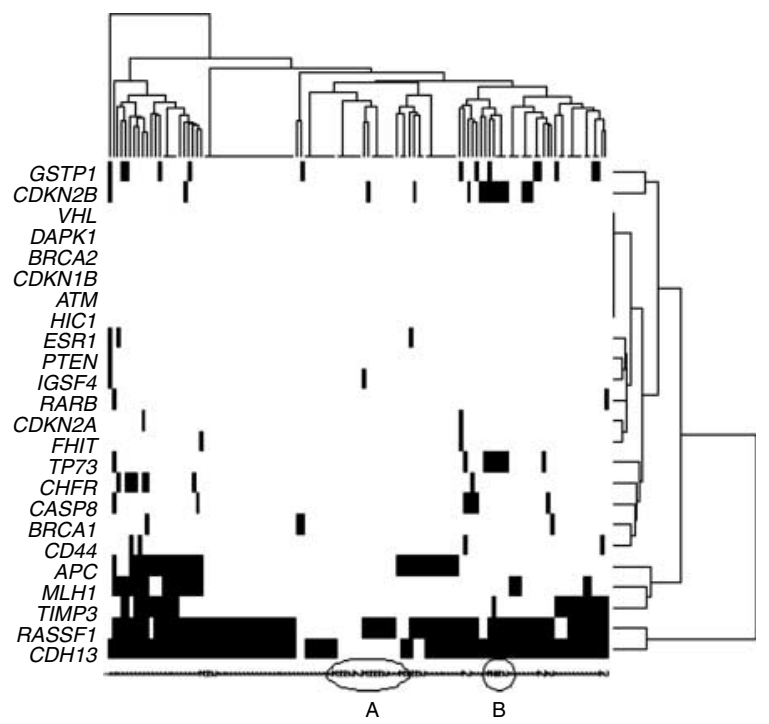

Figure 3 Clustering of samples according to the methylation status of all the 24 genes studied. Black bars correspond to methylated genes, white bars to unmethylated genes. 
Methylation status seemed to cluster tumours best as per grade. Most of the grade 3 tumours clustered, irrespective of their endometrioid or serous background. Clustering of the samples according to the methylation status of all the 24 genes studied is shown in Fig. 3. The red bars correspond to methylated genes, and the green bars correspond to unmethylated genes. A subgroup of UPSC cases showed no methylation of CDH13 and partly no methylation of RASSF1A cluster as group A. A second subgroup of UPSC cases did show methylation of these genes together with methylation of $C D K N 2 B$ and/or TP73 and clustered as group B.

Using logistic regression, $C D H 13$ and $T P 73$ were found to be the best predictors of EEC and UPSC histology. Almost $90 \%$ of EEC and $70 \%$ of UPSC could be predicted with $C D H 13$ (regression coefficient 12.4; 95\% CI 4.19-36.89) and TP73 (regression coefficient 0.07 ; $95 \%$ CI $0.017-0.35$ ).
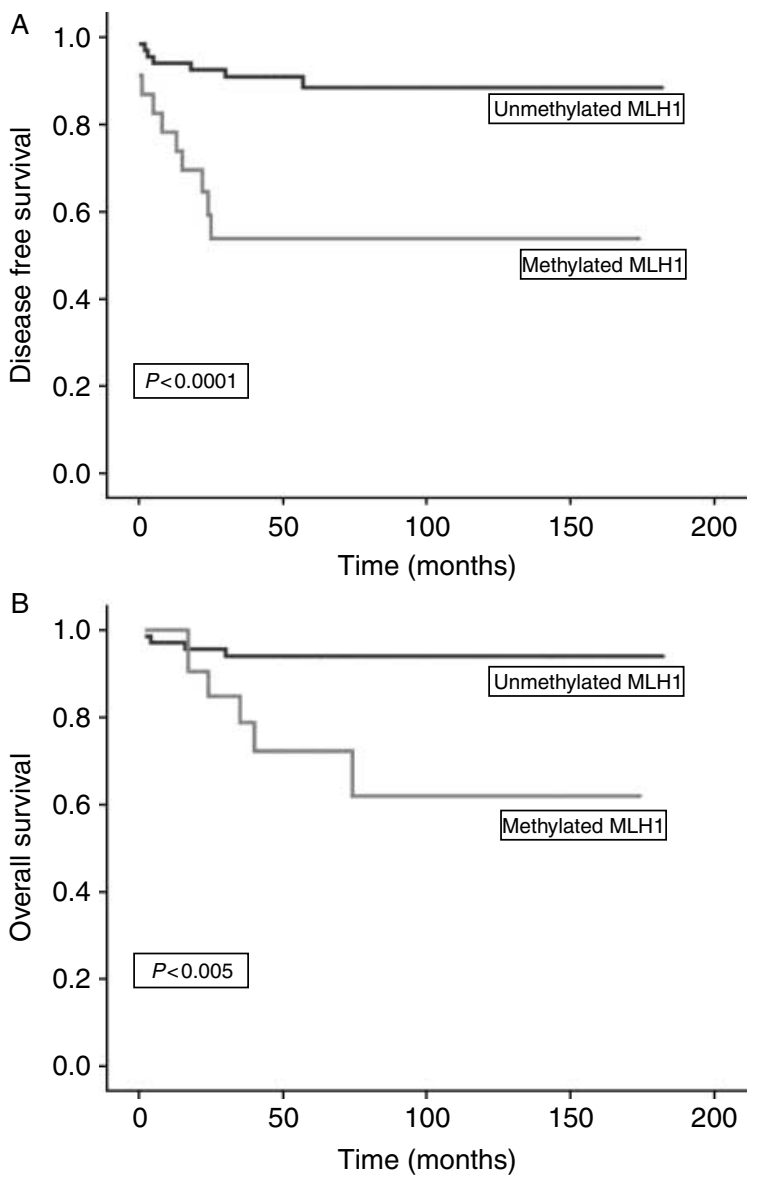

Figure 4 Of the frequently methylated genes, only $M L H 1$ was significantly associated with a shorter DFS $(P<0.0001)$ and OS $(P=0.005)$ in univariate analysis.

\section{Survival analysis}

In EEC, stage and grade showed prognostic value as expected. A CMI of 124 or more was correlated with a shorter disease-free survival (DFS) and overall survival (OS; $P=0.004$ and $P=0.009$ respectively). Of the frequently methylated genes, only $M L H I$ was significantly associated with a shorter DFS $(P<0.0001)$ and $\mathrm{OS}(P=0.005)$ in univariate analysis (Fig. 4). In a multivariate model together with stage, grade, depth of myometrial invasion and CMI, only MLH1 methylation emerged as an additional prognostic factor to stage for DFS $(P=0.002)$. p53 expression was not correlated with survival.

\section{Discussion}

The aim of this study was to compare methylation status of some common TSGs to arrive at a methylation signature of EEC and UPSC that could be of additional value in the correct diagnosis of the two entities. Furthermore, their prognostic value was evaluated. The results indicate that the pattern of gene promoter methylation is indeed associated with the histological subtype of endometrial cancer. These particular characteristics can firstly give insight into the carcinogenetic pathways altered in these tumour types. Secondly, a panel of these methylation biomarkers could be useful to distinguish between EEC and UPSC in daily pathology practice, which is yet, based on histology and p53 immunohistochemistry, often not easy. Lastly, methylation status could be used for the assessment of prognosis of EEC. The fact that MS-MLPA requires only a small amount of DNA which can be paraffin derived is of great practical value to this end.

Overall methylation (as reflected by the CMI) was lower in UPSC, and of the six tumours showing no methylation at all, five were UPSC. This indicates that carcinogenesis of UPSC may be less dependent on promoter methylation, at least for the genes studied. The methylation of mammalian genomic DNA is catalyzed by DNA methyltransferases (DNMTs). Liao et al. (2008) identified two distinct DNMT1 protein expression patterns in endometrial carcinoma. Expression was significantly higher in EEC compared to UPSC. These results concur with observations by Xiong et al. (2005) that upregulation of DNMTs mRNA was detected in EEC, while downregulation of DNMTs occurred in UPSC. The lower overall methylation frequency and the lower quantitative methylation levels found in UPSC might be partly explained by this phenomenon. 
Our results showed promoter methylation of CDH13, MLH1 and TIMP3 to be typical for EEC, while $C D K N 2 B$ and $T P 73$ methylation characterized UPSC. Methylation of $C D H 13$ and TP73 predicted the correct tumour type in almost $90 \%$ of EEC and $70 \%$ of UPSC in logistic regression. Previous studies in EEC usually evaluated single genes. Frequent methylation for TIMP3 (Kang et al. 2006) and $C D H 13$ (Suehiro et al. 2008) in the present study concurs with previously published results in endometrial cancer. Methylation of the $M L H 1$ promoter is also a wellrecognized phenomenon in (sporadic) EEC (Simpkins et al. 1999, Salvesen et al. 2000a, Zighelboim et al. 2007a,b, Esteller 2008). In consensus with our study, MLH1 was shown to be methylated in 20-30\% of cases in previous studies (Salvesen et al. 2000b, Zighelboim et al. 2007a). Methylation of MLH1 and subsequent lack of mRNA expression are thought to be an epigenetic silencing mechanism associated with MSI in sporadic endometrial cancers. MSI is known to be present in about $25 \%$ of endometrial cancers and has been found exclusively in EEC (Risinger et al. 1993, Levine et al. 1998). As expected, we showed that MLHI was never methylated in UPSC.

Only a few studies have included, often small numbers, of UPSC. Therefore, previously published data have to be interpreted with caution. Risinger et al. (2003) found no promoter methylation in UPSC at all. For $M L H 1, D A P K, B R C A 1$ and $p 16$, this is in line with our results. However, in our study, RASSF1 was frequently methylated in both EEC and UPSC. Moreover, we suggest that methylation of TP73 and $C D K N 2 B(p 15)$ is relatively frequently observed in UPSC as compared to EEC (20 vs $4 \%$ and 27 vs $9 \%$ ). Evaluation of TP73 for epigenetic changes has shown aberrant promoter methylation in $\sim 20 \%$ of UPSC. The $p 53$-related $p 73$ gene shares functional similarities with $p 53$, including the ability to transactivate $p 53$ regulated genes, inhibit cell growth and induce apoptosis (reviewed by Stiewe \& Putzer (2002)). For this reason, it has been proposed that $p 73$ is altered more frequently in cases without p53 mutations. However, in UPSC, which often contain p53 mutations, we found no correlation between $p 73$ methylation and p53 staining. This might indicate that dysfunction of $p 53$ and $p 73$ is not exclusive. Since the transcription factor E2F1 can induce p73 protein expression in a $p 53$-deficient background (Irwin et al. 2000), silencing of $p 73$ could be an important mechanism for escape from p53-independent apoptosis. In different types of tumours, $p 73$ methylation is associated with aggressive behaviour, bad response to conventional chemotherapy and a worse prognosis, suggesting a relationship between $p 73$ inactivation and aggressiveness of tumours (Kuo et al. 2009).

We found RASSF1 and $A P C$ to be frequently methylated in both EEC and UPSC without significant preference for either tumour type. As in our present study, RASSF1 was shown to be frequently methylated in EEC (Arafa et al. 2008, Pallares et al. 2008). However, where we found frequent methylation for RASSF 1 in UPSC in line with Liao et al. (2008) and Pallares et al. (2008) found less RASSF1 methylation in UPSC (20\%) than in EEC (61.5\%). The high frequency of $A P C$ methylation is in line with published data, in which the methylation level reported ranged between 22 and 46\% (Moreno-Bueno et al. 2002, Pijnenborg et al. 2004, Banno et al. 2006). As in our study, Ignatov et al. (2009) recently showed no significant difference between the percentage of EEC (59\%) and UPSC (47\%) cases methylated for APC.

The set of genes that we used in the present study was previously studied by Joensuu et al. (2008) in hereditary colorectal and endometrial cancers. The frequently methylated genes in our sporadic EEC correspond to those found in hereditary endometrial cancer, except for CDKN2A and MLH1. CDKN2A (encoding $\mathrm{p} 14^{\mathrm{INK}}$ ) was found to be frequently methylated in the hereditary cases (Joensuu et al. 2008), whereas $M L H 1$ was frequently methylated in our sporadic cases. This suggests that sporadic and hereditary EEC may differ in methylation patterns.

Since mixed histological patterns do occur and diagnosis of UPSC on morphological features can be difficult, the histological classification used as a reference may be disputable. In some cases, there was discordance between pathologists regarding histological classification. These mixed- and disputed cases could obscure a more distinct subtype-specific methylation pattern. Hence, this tumour type-specific methylation pattern seemed not sufficiently differentiating to be of clinical use above histological features and p53 immunohistochemical staining. A more differentiating tumour type-specific methylation signature for diagnostic purposes needs further studies and validation. Prominent was the clustering of the grade 3 tumours, irrespective of their histological classification. This may point to, in part, common epigenetic events in high grade endometrial carcinoma irrespective of their EEC or UPSC origin. Therefore, a methylation assay might be of less added value in distinguishing grade 3 EEC and UPSC.

Contradictory results have been described as to the prognostic value of $\mathrm{MLHI}$ methylation in endometrial carcinoma. In our study, MLH1 methylation was significantly associated with a shorter DFS and OS in 
EEC patients. In a multivariate model together with stage, grade and depth of myometrial invasion, $M L H 1$ methylation emerged as an additional prognostic factor to stage for DFS. At variance with our results, survival tended to be better for patients with methylated MLHI tumours in a study by Salvesen et al. (2000b), although statistical significance was not reached in that particular study. Others did not find a trend of $M L H 1$ methylation status for survival at all (Zighelboim et al. 2007a,b), neither MLH1 methylation seemed to be predictive for the development of recurrences in stage I endometrial carcinoma (Pijnenborg et al. 2004). Where we only included EEC cases in survival analysis, Salvesen et al. (2000b) evaluated both EEC and UPSC in their survival analyses. The underlying heterogeneity of patient populations might therefore explain some of the discrepancies described here. The methods used to assess $M L H 1$ methylation could also partly explain the variability of results. Often different $\mathrm{CpG}$ islands within the same promoter are studied by different methods. Moreover, Varley et al. (2009) recently showed an unexpected heterogeneous pattern of $\mathrm{MLH1}$ promoter methylation within individual endometrial carcinomas.

In the present study, patients of all stages were included. In a subgroup analysis of stage I and II EEC patients, $M L H 1$ methylation retained its prognostic significance, while significance was lost in stage III/IV patients, indicating that $M L H 1$ methylation seems to be especially prognostically important in low stage patients. This is congruent with the observation of MLH1 methylation being present in $7-80 \%$ of the atypical endometrial hyperplasias, suggesting that MLH1 methylation is an early event in the tumourigenesis of sporadic EEC (Esteller et al. 1999, Horowitz et al. 2002).

In conclusion, promoter methylation for common TSGs is more frequent in EEC than in UPSC. Methylation of $C D H 13, M L H 1$ and TIMP3 seems to be characteristic for EEC, and methylation of $C D K N 2 B$ and TP73 seems to be characteristic for UPSC. Methylation of $C D H 13$ and $T P 73$ predicted the correct tumour type in almost $90 \%$ of EEC and 70\% of UPSC, which is promising as a diagnostic test but requires further validation. Furthermore, high methylation, and especially methylation of $M L H 1$, may have prognostic value in EEC.

\section{Supplementary data}

This is linked to the online version of the paper at http://dx. doi.org/10.1677/ERC-10-0014.

\section{Declaration of interest}

The authors declare that there is no conflict of interest that could be perceived as prejudicing the impartiality of the research reported.

\section{Funding}

This work was supported by the Dutch Cancer Society project 2009-4375.

\section{Acknowledgements}

We thank Mrs Karijn Suijkerbuijk, MD and Mr Marc Vooijs, $\mathrm{PhD}$, for their technical advice.

\section{References}

Arafa M, Kridelka F, Mathias V, Vanbellinghen JF, Renard I, Foidart JM, Boniver J \& Delvenne P 2008 High frequency of RASSF1A and RARb2 gene promoter methylation in morphologically normal endometrium adjacent to endometrioid adenocarcinoma. Histopathology 53 525-532.

Banno K, Yanokura M, Susumu N, Kawaguchi M, Hirao N, Hirasawa A, Tsukazaki K \& Aoki D 2006 Relationship of the aberrant DNA hypermethylation of cancer-related genes with carcinogenesis of endometrial cancer. Oncology Reports 16 1189-1196.

Baylin SB \& Herman JG 2000 DNA hypermethylation in tumorigenesis: epigenetics joins genetics. Trends in Genetics 16 168-174.

Bocker T, Ruschoff J \& Fishel R 1999 Molecular diagnostics of cancer predisposition: hereditary non-polyposis colorectal carcinoma and mismatch repair defects. Biochimica et Biophysica Acta 1423 O1-O10.

Chan QK, Khoo US, Chan KY, Ngan HY, Li SS, Chiu PM, Man LS, Ip PP, Xue WC \& Cheung AN 2005 Promoter methylation and differential expression of pi-class glutathione $S$-transferase in endometrial carcinoma. Journal of Molecular Diagnostics 7 8-16.

Costello JF, Fruhwald MC, Smiraglia DJ, Rush LJ, Robertson GP, Gao X, Wright FA, Feramisco JD, Peltomaki P, Lang JC et al. 2000 Aberrant CpG-island methylation has non-random and tumour-type-specific patterns. Nature Genetics 24 132-138.

Creasman WT, Odicino F, Maisonneuve P, Quinn MA, Beller U, Benedet JL, Heintz AP, Ngan HY \& Pecorelli S 2006 Carcinoma of the corpus uteri. FIGO 6th Annual Report on the Results of Treatment in Gynecological Cancer. International Journal of Gynaecology and Obstetrics 95 (Supplement 1) S105-S143.

van Diest PJ 2002 No consent should be needed for using leftover body material for scientific purposes. BMJ 325 648-651.

Esteller M 2008 Epigenetics in cancer. New England Journal of Medicine 358 1148-1159. 
Esteller M, Catasus L, Matias-Guiu X, Mutter GL, Prat J, Baylin SB \& Herman JG 1999 hMLH1 promoter hypermethylation is an early event in human endometrial tumorigenesis. American Journal of Pathology 155 1767-1772.

Furlan D, Carnevali I, Marcomini B, Cerutti R, Dainese E, Capella C \& Riva C 2006 The high frequency of de novo promoter methylation in synchronous primary endometrial and ovarian carcinomas. Clinical Cancer Research 12 3329-3336.

Guida M, Sanguedolce F, Bufo P, Di Spiezio SA, Bifulco G, Nappi C \& Pannone G 2009 Aberrant DNA hypermethylation of hMLH-1 and CDKN2A/p16 genes in benign, premalignant and malignant endometrial lesions. European Journal of Gynaecological Oncology 30 267-270.

Gylling A, Abdel-Rahman WM, Juhola M, Nuorva K, Hautala E, Jarvinen HJ, Mecklin JP, Aarnio M \& Peltomaki P 2007 Is gastric cancer part of the tumour spectrum of hereditary non-polyposis colorectal cancer? A molecular genetic study Gut 56 926-933.

Horowitz N, Pinto K, Mutch DG, Herzog TJ, Rader JS, Gibb R, Bocker-Edmonston T \& Goodfellow PJ 2002 Microsatellite instability, MLH1 promoter methylation, and loss of mismatch repair in endometrial cancer and concomitant atypical hyperplasia. Gynecologic Oncology 86 62-68.

Ignatov A, Bischoff J, Ignatov T, Schwarzenau C, Krebs T, Kuester D, Costa SD, Roessner A, Semczuk A \& Schneider-Stock R 2009 APC promoter hypermethylation is an early event in endometrial tumorigenesis. Cancer Science 101 321-327.

Irwin M, Marin MC, Phillips AC, Seelan RS, Smith DI, Liu W, Flores ER, Tsai KY, Jacks T, Vousden KH et al. 2000 Role for the p53 homologue p73 in E2F-1-induced apoptosis. Nature 407 645-648.

Jemal A, Siegel R, Ward E, Hao Y, Xu J \& Thun MJ 2009 Cancer statistics, 2009. CA: A Cancer Journal for Clinicians 59 225-249.

Joensuu EI, Abdel-Rahman WM, Ollikainen M, Ruosaari S, Knuutila S \& Peltomaki P 2008 Epigenetic signatures of familial cancer are characteristic of tumor type and family category. Cancer Research 68 4597-4605.

Jones PA \& Baylin SB 2002 The fundamental role of epigenetic events in cancer. Nature Reviews. Genetics 3 415-428.

Kanaya T, Kyo S, Maida Y, Yatabe N, Tanaka M, Nakamura M \& Inoue M 2003 Frequent hypermethylation of MLH1 promoter in normal endometrium of patients with endometrial cancers. Oncogene 22 2352-2360.

Kang S, Kim JW, Kang GH, Lee S, Park NH, Song YS, Park SY, Kang SB \& Lee HP 2006 Comparison of DNA hypermethylation patterns in different types of uterine cancer: cervical squamous cell carcinoma, cervical adenocarcinoma and endometrial adenocarcinoma. International Journal of Cancer 118 2168-2171.
Kuo LT, Kuo KT, Lee MJ, Wei CC, Scaravilli F, Tsai JC, Tseng HM, Kuo MF \& Tu YK 2009 Correlation among pathology, genetic and epigenetic profiles, and clinical outcome in oligodendroglial tumors. International Journal of Cancer 124 2872-2879.

Levine RL, Cargile CB, Blazes MS, van Rees B, Kurman RJ \& Ellenson LH 1998 PTEN mutations and microsatellite instability in complex atypical hyperplasia, a precursor lesion to uterine endometrioid carcinoma. Cancer Research 58 3254-3258.

Liao X, Siu MK, Chan KY, Wong ES, Ngan HY, Chan QK, Li AS, Khoo US \& Cheung AN 2008 Hypermethylation of RAS effector related genes and DNA methyltransferase 1 expression in endometrial carcinogenesis. International Journal of Cancer 123 296-302.

Macdonald ND, Salvesen HB, Ryan A, Malatos S, Stefansson I, Iversen OE, Akslen LA, Das S \& Jacobs IJ 2004 Molecular differences between RER + and RER sporadic endometrial carcinomas in a large populationbased series. International Journal of Gynecological Cancer 14 957-965.

Moreno-Bueno G, Hardisson D, Sanchez C, Sarrio D, Cassia R, Garcia-Rostan G, Prat J, Guo M, Herman JG, MatiasGuiu X et al. 2002 Abnormalities of the APC/ $\beta$-catenin pathway in endometrial cancer. Oncogene 21 7981-7990.

Nygren AO, Ameziane N, Duarte HM, Vijzelaar RN, Waisfisz Q, Hess CJ, Schouten JP \& Errami A 2005 Methylation-specific MLPA (MS-MLPA): simultaneous detection of $\mathrm{CpG}$ methylation and copy number changes of up to 40 sequences. Nucleic Acids Research 33 e128.

Pallares J, Velasco A, Eritja N, Santacana M, Dolcet X, Cuatrecasas M, Palomar-Asenjo V, Catasus L, Prat J \& Matias-Guiu X 2008 Promoter hypermethylation and reduced expression of RASSF1A are frequent molecular alterations of endometrial carcinoma. Modern Pathology 21 691-699.

Pijnenborg JM, Dam-de Veen GC, de Haan J, van Engeland M \& Groothuis PG 2004 Defective mismatch repair and the development of recurrent endometrial carcinoma. Gynecologic Oncology 94 550-559.

Risinger JI, Berchuck A, Kohler MF, Watson P, Lynch HT \& Boyd J 1993 Genetic instability of microsatellites in endometrial carcinoma. Cancer Research 53 5100-5103.

Risinger JI, Maxwell GL, Berchuck A \& Barrett JC 2003 Promoter hypermethylation as an epigenetic component in type I and type II endometrial cancers. Annals of the New York Academy of Sciences 983 208-212.

Salvesen HB, Das S \& Akslen LA 2000a Loss of nuclear p16 protein expression is not associated with promoter methylation but defines a subgroup of aggressive endometrial carcinomas with poor prognosis. Clinical Cancer Research 6 153-159.

Salvesen HB, MacDonald N, Ryan A, Iversen OE, Jacobs IJ, Akslen LA \& Das S 2000b Methylation of hMLH1 in a population-based series of endometrial carcinomas. Clinical Cancer Research 6 3607-3613. 
Salvesen HB, MacDonald N, Ryan A, Jacobs IJ, Lynch ED, Akslen LA \& Das S 2001 PTEN methylation is associated with advanced stage and microsatellite instability in endometrial carcinoma. International Journal of Cancer $9122-26$.

Scholten AN, Smit VT, Beerman H, van Putten WL \& Creutzberg CL 2004 Prognostic significance and interobserver variability of histologic grading systems for endometrial carcinoma. Cancer 100 764-772.

Sherman ME, Bitterman P, Rosenshein NB, Delgado G \& Kurman RJ 1992 Uterine serous carcinoma. A morphologically diverse neoplasm with unifying clinicopathologic features. American Journal of Surgical Pathology 16 600-610.

Simpkins SB, Bocker T, Swisher EM, Mutch DG, Gersell DJ, Kovatich AJ, Palazzo JP, Fishel R \& Goodfellow PJ 1999 MLH1 promoter methylation and gene silencing is the primary cause of microsatellite instability in sporadic endometrial cancers. Human Molecular Genetics $\mathbf{8}$ 661-666.

Stiewe T \& Putzer BM 2002 Role of p73 in malignancy: tumor suppressor or oncogene? Cell Death and Differentiation 9 237-245.

Suehiro Y, Okada T, Okada T, Anno K, Okayama N, Ueno K, Hiura M, Nakamura M, Kondo T, Oga A et al. 2008 Aneuploidy predicts outcome in patients with endometrial carcinoma and is related to lack of CDH13 hypermethylation. Clinical Cancer Research 14 3354-3361.

Suijkerbuijk KP, Fackler MJ, Sukumar S, van Gils CH, van Laar T, van der Wall E, Vooijs M \& van Diest PJ
2008 Methylation is less abundant in BRCA1-associated compared with sporadic breast cancer. Annals of Oncology 19 1870-1874.

Varley KE, Mutch DG, Edmonston TB, Goodfellow PJ \& Mitra RD 2009 Intra-tumor heterogeneity of MLH1 promoter methylation revealed by deep single molecule bisulfite sequencing. Nucleic Acids Research 37 4603-4612.

Xie R, Loose DS, Shipley GL, Xie S, Bassett RL Jr \& Broaddus RR 2007 Hypomethylation-induced expression of S100A4 in endometrial carcinoma. Modern Pathology 20 1045-1054.

Xiong Y, Dowdy SC, Xue A, Shujuan J, Eberhardt NL, Podratz KC \& Jiang SW 2005 Opposite alterations of DNA methyltransferase gene expression in endometrioid and serous endometrial cancers. Gynecologic Oncology 96 601-609.

Yang HJ, Liu VW, Wang Y, Tsang PC \& Ngan HY 2006 Differential DNA methylation profiles in gynecological cancers and correlation with clinico-pathological data. BMC Cancer 6212.

Zighelboim I, Goodfellow PJ, Gao F, Gibb RK, Powell MA, Rader JS \& Mutch DG 2007a Microsatellite instability and epigenetic inactivation of MLH1 and outcome of patients with endometrial carcinomas of the endometrioid type. Journal of Clinical Oncology 25 2042-2048.

Zighelboim I, Goodfellow PJ, Schmidt AP, Walls KC, Mallon MA, Mutch DG, Yan PS, Huang TH \& Powell MA 2007b Differential methylation hybridization array of endometrial cancers reveals two novel cancer-specific methylation markers. Clinical Cancer Research 13 2882-2889. 